\title{
Affective alterations in patients with Cushing's syndrome in remission are associated with decreased BDNF and cortisone levels
}

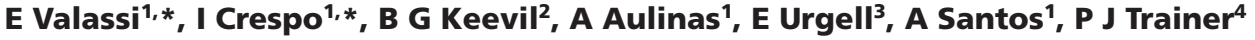 \\ and $\mathbf{S} \mathbf{M}$ Webb'
}

${ }^{1}$ Endocrinology/Medicine Department, Hospital Sant Pau, Centro de Investigación Biomédica en Red de Enfermedades Raras (CIBERER, Unidad 747), IIB-Sant Pau, ISCIII and Universitat Autònoma de Barcelona (UAB), Barcelona, Spain, ²Department of Clinical Biochemistry, University Hospital of South Manchester, Manchester, United Kingdom, ${ }^{3}$ Biochemistry Department, Hospital Sant Pau, Barcelona, Spain, and ${ }^{4}$ Department of Endocrinology, The Christie NHS Foundation Trust, Manchester, United Kingdom *(E Valassi and I Crespo contributed equally to this work)

\author{
Correspondence \\ should be addressed \\ to E Valassi \\ Email \\ EValassi@santpau.cat
}

\section{Abstract}

Objective: Affective alterations and poorer quality of life often persist in patients with Cushing's syndrome (CS) in remission. Brain-derived neurotrophic factor (BDNF) regulates the hypothalamic-pituitary-adrenal axis (HPA) and is highly expressed in brain areas controlling mood and response to stress. Our aims were to assess affective alterations after long-term remission of CS and evaluate whether they are associated with serum BDNF, salivary cortisol (SalF) and/or cortisone (SalE) concentrations.

Subjects and methods: Thirty-six CS patients in remission (32 females/4 males; mean age ( \pm S.D.), $48.8 \pm 11.8$ years; median duration of remission, 72 months) and 36 gender-, age- and BMI-matched controls were included. Beck Depression Inventory-II (BDI-II), Center for Epidemiological Studies Depression Scale (CES-D), Positive Affect Negative Affect Scale (PANAS), State-Trait Anxiety Inventory (STAI), Perceived Stress Scale (PSS) and EuroQoL and CushingQoL questionnaires were completed and measured to evaluate anxiety, depression, stress perception and quality of life $(\mathrm{Q} o \mathrm{~L})$ respectively. Salivary cortisol was measured using liquid chromatography/tandem mass spectrometry (LC/TMS). BDNF was measured in serum using an ELISA.

Results: Remitted CS patients showed worse scores in all questionnaires than controls: $\mathrm{STAl}(P<0.001), \mathrm{BDI}(P<0.001)$, CES-D $(P<0.001)$, PANAS $(P<0.01)$, PSS $(P<0.01)$ and EuroQoL $(P<0.01)$. A decrease in BDNF was observed in CS vs controls $(P=0.038)$, and low BDNF was associated with more anxiety $(r=-0.247, P=0.037)$, depression ( $r=-0.249$, $P=0.035)$, stress $(r=-0.277, P=0.019)$ and affective balance $(r=0.243, P=0.04)$. Morning salivary cortisone was inversely associated with trait anxiety $(r=-0.377, P=0.040)$ and depressed affect $(r=-0.392, P=0.032)$ in CS patients. Delay to diagnosis was associated with depressive symptoms (BDI-II: $r=0.398, P=0.036$ and CES-D: $r=0.449, P=0.017$ ) and CushingQoL scoring $(r=-0.460, P<0.01)$.

Conclusions: Low BDNF levels are associated with affective alterations in 'cured' CS patients, including depression, anxiety and impaired stress perception. Elevated levels of SalE might also be related to poor affective status in these patients.

\section{Introduction}

Cushing's syndrome (CS) is a rare endocrine disorder caused by chronic exposure to cortisol excess (1). Patients with CS show poor neuropsychological status, including
() 2017 European Society of Endocrinology Printed in Great Britain
European Journal of Endocrinology

(2017) 176, 221-231 depression, anxiety and mania, which also affect healthrelated quality of life (QoL) $(2,3,4,5,6)$. Recent evidence indicates that some of the behavioral dysfunctions 
observed in the active phase of CS do not fully revert after correction of hypercortisolism $(7,8,9,10,11,12$, $13,14,15)$. In particular, an increased prevalence of affective alterations, such as anxiety, emotional lability and apathy, has been described in patients with Cushing's disease (CD) at an average of 11 years of remission, as compared not only with healthy subjects but also with patients who had been treated for non-functioning pituitary macroadenomas (16). As a matter of fact, recent magnetic resonance (MR) imaging studies showed structural and functional brain damage in CS patients for a long-term after remission, mainly at those brain regions, rich in glucocorticoid receptors (GR), which are involved in stress reactivity and emotional processing $(17,18,19$, 20). These findings suggest that previous over-exposure to cortisol may cause irreversible effects on brain, thus leading to sustained psychological symptomatology after eucortisolism is reached (21). Of note, Dorn et al. reported an inverse association between persistent psychopathology and morning cortisol values in CS patients in long-term remission, indicating that a sustained derangement of the hypothalamic-pituitary-adrenal axis after restoration of eucortisolism may increase the individual vulnerability to stressors (8).

Brain-derived neurotrophic factor (BDNF), a member of the nerve growth factor (NGF) family, is a prominent mediator of neuronal differentiation, survival and plasticity and is highly expressed in the hippocampus and prefrontal cortex, which constitute a neural circuitry controlling mood and response to stress (22). Decreased BDNF expression in these regions has been described in several models of rodents exposed to chronic stress and has been associated with depression-like behavior (23). In humans, serum BDNF levels are lower in stressinduced affective disorders, including major depression disorder (MDD), compared with healthy controls, and are increased by antidepressant treatment (22). Noteworthy, BDNF may be involved in the regulation of the hypothalamic-pituitary-adrenal axis (HPA) in that the intracerebroventricular administration of this neurotrophin enhances the expression of corticotrophinreleasing factor (CRF) in the hypothalamus of adult rats, leading to the elevation of plasma corticosterone levels (24).

Assessment of salivary cortisol (SalF), a surrogate for free serum cortisol (SerF), is routinely used as a biomarker of psychological stress and depressive symptoms (25) and has also been advocated in clinical practice as an accurate test to diagnose CS (26) or ascertain postoperative outcome in CD patients (27). Yet, because of the abundance in the parotid gland of $11 \beta$-hydroxysteroid dehydrogenase type 2 (11ß-HSD2), which converts cortisol (SalF) to cortisone (SalE), the latter is the most abundant glucocorticoid in saliva (28). Indeed, it has been recently demonstrated that salivary cortisone (SalE) is highly correlated to SerF concentrations under both basal and stimulated conditions, and, in contrast to SalF, is detectable even in the presence of low SerF levels $(29,30)$. These findings suggest that SalE could be more reliable than SalF in assessing the biological activity of cortisol. To the best of our knowledge, no data have been published thus far on SalE in CS patients in long-term remission.

We hypothesized that BDNF is decreased in 'cured' CS and modulates mood and stress perception in these patients. Moreover, given that SalE may be a more accurate surrogate marker of SerF than SalF, and serum cortisol is associated with psychological impairment in CS patients in long-term remission, we hypothesized that morning and late-night SalE concentrations are associated with altered emotional status in these patients.

Thus, the aim of this study was to examine the relationship between serum BDNF levels, depressive and anxiety symptoms, impairment of stress perception and emotional status, as well as poor HRQoL, in patients treated for CS. In addition, we aimed at determining if there was an association between SalF and/or SalE, as assessed by a highly sensitive and specific liquid chromatography/tandem mass spectrometry (LC/TMS) method, and depressive symptoms as well as BDNF values in our patients.

\section{Methods}

\section{Subjects}

We studied 36 patients with Cushing's syndrome in remission (32 females and 4 males; mean age ( \pm S.D.), $48.83 \pm 11.8$ years; 20 females (63\%) were premenopausal) who were included successively in our study while attending the endocrine clinic at the Hospital Sant Pau, Barcelona (Spain). They were matched for age, gender and body mass index (BMI) with 36 controls who were recruited through advertisement at the blood donor center of the Hospital Sant Pau, Barcelona (Spain) (Table 1).

The diagnosis of CS was made after clinical, biochemical and radiological evaluation, based on internationally agreed guidelines. All patients had abnormal values on at least two of the following tests: elevated UFC, late-night salivary or serum cortisol, 1-mg overnight dexamethasone suppression test (ODST) or 
Table 1 Clinical characteristics of CS patients in remission and healthy controls. All values are expressed as mean \pm s.D. or as $n$ (\%).

\begin{tabular}{l} 
Characteristics \\
\hline Gender (female/male) \\
Age (years) \\
Body mass index (BMI, $\mathrm{kg} / \mathrm{m}^{2}$ ) \\
Origin of CS: \\
Pituitary adenoma \\
Adrenal adenoma \\
Transsphenoidal surgery \\
Radiotherapy \\
Previous medical treatment with steroidogenesis inhibitors \\
Delay to diagnosis (months) \\
Duration of remission (months) \\
Time from diagnosis to remission (months) \\
Gonadotropin deficiency \\
Growth hormone deficiency \\
Hypothyroidism \\
Salivary cortisol (nmol/L; mean \pm S.D.(range)) \\
Morning \\
Late-night \\
Salivary cortisol (nmol/L; mean \pm S.D.(range)) \\
Morning \\
Late-night \\
Cortisol diurnal rhythm (CDR) \\
Morning SalF/SalE ratio \\
Midnight SalF/SalE ratio
\end{tabular}

*Values are expressed as median (interquartile range)

48-h 2-mg/day low-dose dexamethasone suppression test (LDDST).

Twenty-five patients had Cushing's disease (CD) due to a microadenoma $(n=22)$ or a macroadenoma $(n=3)$. The remaining 11 patients had an adrenal adenoma. All the CD patients underwent transsphenoidal surgery (TSS) from 12 to 288 months previously (median: 78 months), and 6 of them (24\%) also received radiotherapy from 18 to 96 months after unsuccessful surgery $(n=2)$ or relapse $(n=4)$ (median: 54 months). All the patients diagnosed with an adrenal adenoma underwent adrenalectomy from 12 to 312 months previously (median: 54 months).

Twenty patients (56\%) received preoperative treatment with steroidogenesis inhibitors to control clinical symptoms of hypercortisolism from 1 to 22 months (median: 4.6 months) prior to surgery.

Delay to diagnosis was defined as the time elapsed from onset of symptoms, as referred by patients, and final diagnosis of CS.

CS was considered in remission if either adrenal insufficiency was demonstrated (basal morning cortisol $<1002 \mathrm{nmol} / \mathrm{L} \quad(<4 \mu \mathrm{g} / \mathrm{dL})$ and/or undetectable 24-h free urinary cortisol) or morning cortisol suppression ( $<50 \mathrm{nmol} / \mathrm{L}$ and $<1.8 \mu \mathrm{g} / \mathrm{dL})$ after $1 \mathrm{mg}$ dexamethasone overnight was observed. Thirty patients (83\%) had

\begin{tabular}{c}
\hline CS in remission $(n=36)$ \\
\hline $32 / 4$ \\
$48.8 \pm 11.8$ \\
$27 \pm 4.7$ \\
$25(69 \%)$ \\
$11(31 \%)$ \\
$25(69 \%)$ \\
$6(24 \%)$ \\
$20(56 \%)$ \\
$24(41.7)$ \\
$72(153.7)$ \\
$12(6)$ \\
$3(8 \%)$ \\
$5(14 \%)$ \\
$5(14 \%)$
\end{tabular}

\begin{tabular}{|c|c|}
\hline Healthy controls $(n=36)$ & $P$ value \\
\hline $32 / 4$ & 0.99 \\
\hline $48.8 \pm 11.7$ & 0.99 \\
\hline $26.1 \pm 5.7$ & 0.46 \\
\hline
\end{tabular}

$5.8 \pm 3.9(1.4-14.6)$

$1.6 \pm 1.1(0.8-4.9)$

$16.5 \pm 9.9(3.1-39.6)$

$5.9 \pm 6(0.8-26.5)$

$3.6 \pm 2$

$0.39 \pm 0.19$

$0.38+0.31$
$-$

$-$

$-$

$-$

$-$

$-$

$-$

$-$

$$
6.3 \pm 4.1(0.8-21.8) \quad 0.63
$$$$
1.2 \pm 0.9(0.8-4.8) \quad 0.16
$$

$17.1 \pm 9.2(0.8-42.7) \quad 0.81$

$4.4 \pm 3.2(0.8-12.9) \quad 0.23$

$3.7 \pm 2$

$0.37 \pm 0.2$

$0.32+0.23$ received hydrocortisone (HC) replacement for a median of 9 months (range: 3-60 months) after surgery. At the time of study entry, no patient was on HC, for a median of 94 months (range: 5-204 months). Active hypercortisolism was ruled out in all the patients. Duration of remission was defined as the time elapsed from diagnostic confirmation of remission to study entry.

At study entry, all the subjects were evaluated for possible pituitary insufficiency. Three patients (8\%) had growth hormone deficiency (GHD) and were on replacement with recombinant human $\mathrm{GH}$; five women (14\%) were gonadotropin deficient and on estrogen/progesterone hormone replacement; and five (14\%) were hypothyroid, three due to TSH deficiency and two due to primary hypothyroidism (all on L-thyroxine replacement).

Exclusion criteria were active disease, patients with ascertained adrenal insufficiency (i.e. morning cortisol values below $5 \mu \mathrm{g} / \mathrm{dL}$ or stimulated cortisol levels below $18 \mu \mathrm{g} / \mathrm{dL}$ ) (31) and/or taking replacement therapy with hydrocortisone, diabetes mellitus, diagnosis of major depression disorder or other psychiatric condition, and patients taking more than one psychoactive drug (benzodiazepines and selective serotonin reuptake inhibitors-SSRIs). 
During the study visit, patients and controls underwent a fasting blood drawing for the measurement of BDNF. All the subjects were asked to report their daily habits (awakening, lunch/dinner time and bed-time); they used to wake up around 7.30-8 and go to sleep around midnight. They were also given four commercially available cotton devices (Salivette, Sarstedt, Numbrecht, Germany) for collection of morning (between 07:30 and 08:00 h) and late-night (23:30 and 24:00 h) saliva samples on two consecutive days. Subjects were instructed to refrain from brushing their teeth, smoking, eating or drinking other than water for at least $60 \mathrm{~min}$ before sampling. They were also instructed to store the Salivettes, after saliva sampling, at $4^{\circ} \mathrm{C}$ in a home refrigerator and send back by mail within 7 days. The cortisol diurnal rhythm (CDR) was calculated as the ratio between morning salivary cortisol to midnight salivary cortisol. A normal CDR was defined by morning/ midnight ratio of salivary cortisol $>2$ (32).

All subjects gave full informed consent, and the study was approved by the local ethics committee (CEIC, Hospital Sant Pau, Barcelona).

\section{Assays}

Salivary cortisol was measured by liquid-chromatographytandem mass spectrometry (LC/TMS). Salivary cortisol (SalF) and salivary cortisone (SalE) were measured with a LC-MS/MS assay with lower limits of quantitation $0.39 \mathrm{nmol} / \mathrm{L}$ (SalF) and $0.78 \mathrm{nmol} / \mathrm{L}$ (SalE); intra-assay CVs of less than $9.3 \%$ and less than $7.9 \%$; and interassay CVs of less than $9.7 \%$ and less than $10.3 \%$ at $1.8-52.2 \mathrm{nmol} / \mathrm{L}$ of SalF and $3.6-96 \mathrm{nmol} / \mathrm{L}$ of SalE respectively $(28,29)$. The ratio SalF/SalE was calculated as a marker of $11 \beta-H S D 2$ activity (29).

Brain-derived neurotrophic factor (BDNF) measurement in serum was performed by a Quantikine ELISA (R\&D Systems Europe LTD). The limit of detection was less than $20 \mathrm{pg} / \mathrm{mL}$. Interassay variation was $7.6-11.3 \%$ and intra-assay variation $3.8-6.2 \%$.

\section{Measurement of affective state}

State-Trait Anxiety Inventory

State-Trait Anxiety Inventory (STAI) is a self-reported measure that includes two subscales to evaluate two types of anxiety: state anxiety (anxiety related to current events) and trait anxiety (anxiety as a personal characteristic). Each subscale has 20 questions with a four-point scale ranging from 0 to 3 . The total score for each subscale can range from 0 to 60 . Higher scores indicate higher levels of anxiety (33).

\section{Beck Depression Inventory-II}

Beck Depression Inventory-II (BDI-II) is a self-reported measure of the severity of depressive symptoms. It has 21 items with a four-point scale ranging from 0 to 3 . The total score is the sum of each item rating and can range from 0 to 63 . Higher scores indicate more severe depressive symptoms. The BDI-II can be separated into affective and somatic dimensions $(34,35)$.

\section{Center for Epidemiological Studies Depression Scale}

Center for Epidemiological Studies Depression Scale (CES-D) includes 20 items measuring subject frequency rate of depressive symptoms on a four-point scale ranging from 0 to 3. CES-D can be separated into four subscales assessing: (1) depressed affect, (2) vegetative depression, (3) loss of wellbeing and (4) interpersonal relationships. Higher scores indicate more frequency of depressive symptoms (36).

\section{Positive and Negative Affective Schedule}

Positive and Negative Affective Schedule (PANAS) is a selfreported measure of positive and negative emotions in the last week. PANAS consists of 20 words (10 reflect positive affect and 10 negative affect), which are rated from 1 to 5 . Higher score indicates more intensity in the emotion. The affective balance (total score) is calculated as the difference between positive affect and negative affect (37).

\section{Perceived Stress Scale}

Perceived Stress Scale (PSS) measures the perception of situations appraised as unpredictable or uncontrollable over the last month and includes 14 items with a 5-point response scale. A higher score indicates a higher level of perceived stress (38).

\section{Measurements of Quality of Life (QoL) \\ EuroQoL}

EuroQoL is a generic questionnaire of QoL that is divided into 2 parts. EuroQoL-5D profile evaluates five health dimensions (mobility, self-care, usual activities, pain/ 
discomfort and anxiety/depression) with a single item with three possible answers (having no problems, having some or moderate problems and being unable to do/ having extreme problems). EuroQoL-VAS is a visual analogue scale that evaluates the self-perception of current health (39), ranging from 0 (worst possible) to 100 (best possible QoL).

\section{CushingQoL}

CushingQoL is a disease-generated questionnaire, which consists of 12 items referring to problems relevant to CS patients. Each item has five categories of response related to frequency and degree of agreement with the sentence. The total score is the sum of each item-rating (range 12-60) and higher scores indicate better QoL $(6,14)$.

\section{Statistical analysis}

Data were analyzed using SPSS 21.0 statistical package for Windows (SPSS Inc.) with a level of significance of $P<0.05$. All quantitative data are expressed as mean \pm S.D. (Gaussian distribution) or as median (interquartile range) (non-Gaussian distribution). Data distribution was analyzed by the Kolmogorov-Smirnov test. Comparisons between the two groups were performed using Student's $t$-test and Mann-Whitney $U$ test. Correlations among variables were studied using Pearson's correlation coefficient for parametric measures and Spearman's rho for non-parametric measures. Furthermore, stepwise multiple linear regression analyses were performed to assess potential predictors of CushingQoL scoring. A logarithmic transformation of 'delay to diagnosis', a variable which was not normally distributed, was performed before entering it to a multiple regression model.

\section{Results}

\section{Hormone parameters}

No differences in either SalF or SalE were observed between CS patients and healthy controls. The ratio SalF a.m./SalF p.m. and ratio SalF/SalE were also similar in CS and controls (Table 1).

BDNF values were significantly lower in CS patients than controls $(433.5 \pm 278.8 \mathrm{pg} / \mathrm{mL}$ vs $602.8 \pm 391.1 \mathrm{pg} / \mathrm{mL}$, $P=0.038$ ) (Fig. 1).

No differences in BDNF levels were found between patients with CD and patients with an adrenal adenoma or patients receiving surgery alone as compared with those who also underwent radiotherapy.

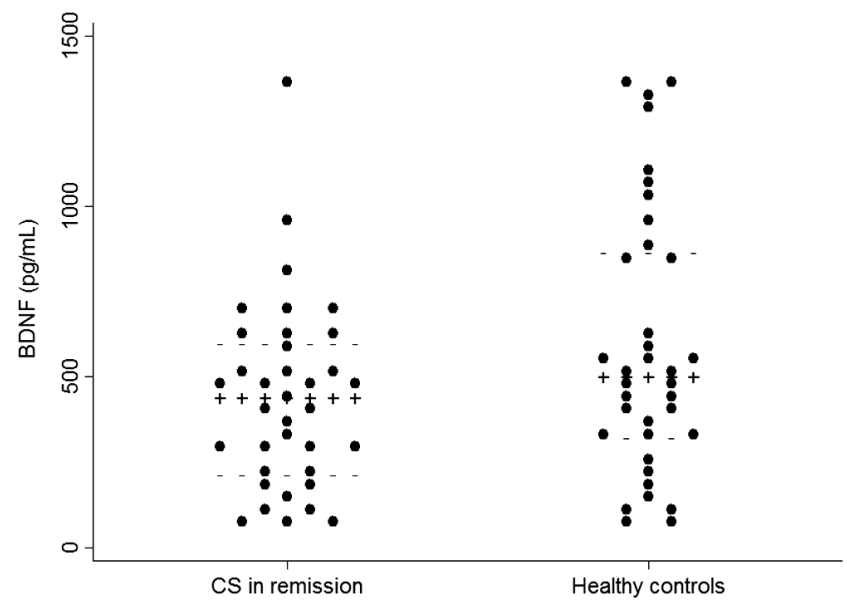

Figure 1

BDNF levels were significantly lower in CS patients in remission $(433.5 \pm 278.8 \mathrm{pg} / \mathrm{mL})$ as compared with healthy controls $(602.8 \pm 391.1 \mathrm{pg} / \mathrm{mL})(* P=0.038)$.

\section{Affective state and QoL}

CS patients showed both higher state and trait anxiety scores than controls (state, $22.9 \pm 13.4$ vs $12.2 \pm 8.1$; trait, $25.8 \pm 13.7$ vs $14.9 \pm 8.5 ; P<0.001$ for both comparisons)

Table 2 Affective state in CS patients in remission and healthy controls.

\begin{tabular}{|c|c|c|c|}
\hline Questionnaires & $\begin{array}{c}\text { CS in remission } \\
(n=36)\end{array}$ & $\begin{array}{l}\text { Healthy controls } \\
\qquad(n=36)\end{array}$ & $P$ value \\
\hline \multicolumn{4}{|l|}{ STAI } \\
\hline Anxiety state & $22.9 \pm 13.4$ & $12.2 \pm 8.1$ & $<0.001$ \\
\hline Anxiety trait & $25.8 \pm 13.7$ & $14.9 \pm 8.5$ & $<0.001$ \\
\hline \multicolumn{4}{|l|}{ BDI-II } \\
\hline Total score & $11.3 \pm 10.2$ & $3.4 \pm 2.9$ & $<0.001$ \\
\hline $\begin{array}{l}\text { Affective } \\
\text { dimension }\end{array}$ & $6.7 \pm 1.3$ & $1.7 \pm 0.3$ & $<0.001$ \\
\hline Somatic dimension & $4.6 \pm 0.5$ & $1.7 \pm 0.3$ & $<0.001$ \\
\hline \multicolumn{4}{|l|}{ CES-D } \\
\hline Total score & $16 \pm 13.2$ & $6.5 \pm 6.4$ & $<0.001$ \\
\hline Depressed affect & $4.6 \pm 0.9$ & $1.4 \pm 0.4$ & 0.001 \\
\hline $\begin{array}{l}\text { Vegetative } \\
\text { depression }\end{array}$ & $5.3 \pm 0.9$ & $2 \pm 0.4$ & 0.001 \\
\hline Loss of well-being & $5.5 \pm 0.6$ & $2.9 \pm 0.5$ & 0.002 \\
\hline $\begin{array}{l}\text { Interpersonal } \\
\text { relationship }\end{array}$ & $0.56 \pm 1.2$ & $0.25 \pm 0.5$ & 0.185 \\
\hline \multicolumn{4}{|l|}{ PANAS } \\
\hline $\begin{array}{l}\text { Affective balance } \\
\text { (or total score) }\end{array}$ & $7.5 \pm 2.4$ & $19.3 \pm 1.8$ & $<0.001$ \\
\hline Positive affect & $26 \pm 8.7$ & $32.9 \pm 9.2$ & 0.002 \\
\hline Negative affect & $18.6 \pm 9.4$ & $13.6 \pm 3.7$ & 0.005 \\
\hline \multicolumn{4}{|l|}{ PSS } \\
\hline Total score & $24.94 \pm 9.8$ & $17.56 \pm 8$ & 0.001 \\
\hline
\end{tabular}

BDI-II, Beck Depression Inventory-II; CESD, Center for Epidemiological Studies Depression Scale; PANAS, Positive and Negative Affective Schedule; PSS, Perceived Stress Scale; STAI, State-Trait Anxiety Inventory. 
Table 3 Significant correlations between questionnaires and clinical parameters.

\begin{tabular}{|c|c|c|c|}
\hline \multirow[b]{2}{*}{ Questionnaires } & \multicolumn{3}{|c|}{ Clinical parameters, $r$} \\
\hline & $\begin{array}{l}\text { BDNF } \\
(\mathrm{pg} / \mathrm{mL})\end{array}$ & $\begin{array}{l}\text { Morning } \\
\text { salivary } \\
\text { cortisone } \\
(\text { SalE) } \\
(\mathrm{nmol} / \mathrm{L})\end{array}$ & $\begin{array}{l}\text { Delay to } \\
\text { diagnosis } \\
\text { (months) }\end{array}$ \\
\hline \multicolumn{4}{|l|}{ STAI } \\
\hline Anxiety state & & & \\
\hline Anxiety trait & $-0.247 *$ & $-0.377^{*}$ & \\
\hline \multicolumn{4}{|l|}{ BDI-II } \\
\hline Total score & & & $0.398^{*}$ \\
\hline $\begin{array}{l}\text { Affective dimension } \\
\text { Somatic dimension }\end{array}$ & $-0.249 *$ & & \\
\hline \multicolumn{4}{|l|}{ CES-D } \\
\hline Total score & & & $0.449 *$ \\
\hline Depressed affect & & $-0.392 *$ & \\
\hline Vegetative depression & & & \\
\hline Loss of wellbeing & & & \\
\hline $\begin{array}{l}\text { Interpersonal } \\
\text { relationship }\end{array}$ & & & \\
\hline \multicolumn{4}{|l|}{ PANAS } \\
\hline $\begin{array}{l}\text { Affective balance } \\
\text { (total score) }\end{array}$ & $0.243^{*}$ & & \\
\hline $\begin{array}{l}\text { Positive affect } \\
\text { Negative affect }\end{array}$ & $0.295^{*}$ & & \\
\hline \multicolumn{4}{|l|}{ PSS } \\
\hline Total score & $-0.277^{*}$ & & \\
\hline \multicolumn{4}{|l|}{ CushingQoL } \\
\hline Total score & & & $-0.460 * *$ \\
\hline
\end{tabular}

(Table 2). Total score of BDI-II was higher in CS patients than controls, indicating more depressive symptoms $(11.3 \pm 10.2$ vs $3.4 \pm 2.9, P<0.001)$. CS patients scored worse on affective and somatic subscales of BDI-II than controls (affective, $6.7 \pm 1.3$ vs $1.7 \pm 0.3$; somatic, $4.6 \pm 0.5$ vs $1.7 \pm 0.3 ; P<0.001$ for both comparisons) (Table 2). Twenty-four CS patients (67\%) showed minimal symptoms, 4 (11\%) mild symptoms, 5 (14\%) showed moderate symptoms and three (8\%) severe symptoms of depression.

CS patients also reported greater total depressive symptoms than controls using the CES-D $(16 \pm 13.2$ vs $6.5 \pm 6.4 ; P<0.001)$. CS patients scored higher on subscales of depressed affect, vegetative depression and loss of wellbeing compared to healthy controls (depressed affect, $4.6 \pm 0.9$ vs $1.4 \pm 0.4$; vegetative depression, $5.3 \pm 0.9$ vs $2 \pm 0.4$; loss of wellbeing, $5.5 \pm 0.6$ vs $2.9 \pm 0.5 ; P<0.01$ for all comparisons). No differences in the subscale of interpersonal relationships were found between CS and controls. On PANAS, the affective balance score was lower in CS patients than healthy controls $(7.5 \pm 2.4$ vs $19.3 \pm 1.8 ; P<0.001)$. CS patients scored higher on negative affect and lower on positive affect than controls, as assessed by PANAS (negative affect, $18.6 \pm 9.4$ vs $13.6 \pm 3.7$; positive affect, $26 \pm 8.7$ vs $32.9 \pm 9.2 ; P<0.01$ for both comparisons) (Table 2).

Total score of PSS was higher in CS patients than healthy control $(24.9 \pm 9.8$ vs $17.6 \pm 8 ; P<0.01)$, indicating greater stress perception (Table 2 ).

CS patients showed poorer QoL than healthy controls, as assessed by EuroQoL-VAS $(70.9 \pm 19.8$ vs $84.5 \pm 14.5$; $P<0.01)$. Cushing QoL in CS patients was $40 \pm 9.9$.

No differences in these parameters were observed between $\mathrm{CD}$ patients as compared with those with an adrenal adenoma.

\section{Relationship between hormone values, affective state and QoL}

BDNF levels were negatively correlated with the trait anxiety score of STAI $(r=-0.247, P=0.037)$, the affective dimension score of BDI-II $(r=-0.249, P=0.035)$ and the perception of stress $(r=-0.277, P=0.019)$ measured by PSS. Moreover, BDNF was correlated with the affective balance and positive affect of PANAS (affective balance, $r=0.243, \quad P=0.04$; positive affect, $r=0.295, \quad P=0.012$ ). These associations remained significant after correcting for age (Table 3).

There was an inverse correlation between level of morning salivary cortisone and scores on trait anxiety of STAI $(r=-0.377, P=0.040)$ and depressed affect of CES-D ( $r=-0.392, P=0.032$ ) (Table 3 and Fig. 2). Midnight SalF/ SalE ratio was negatively correlated with BDNF levels ( $r=-0.401, P=0.035$ ) in CS patients but not in controls.

On the other hand, delay to diagnosis was related to the total score of BDI-II and total score of CES-D (BDI-II: $r=0.398, P=0.036$ and CES-D: $r=0.449, P=0.017)$, two measurements of depressive symptoms and CushingQoL scores $(r=-0.460, P<0.01)$ (Table 3 and Fig. 3). These correlations lost significance after correction for age. We did not find any correlations between duration of remission and both affective state and QoL measurements.

When CushingQoL scoring was entered as a dependent variable and age, delay to diagnosis and total score of BDI-II as independent variables in a forward stepwise regression model, total score of BDI-II was the only predictor of CushingQoL $(\beta=-0.647 ; P<0.001)$ in CS patients. 

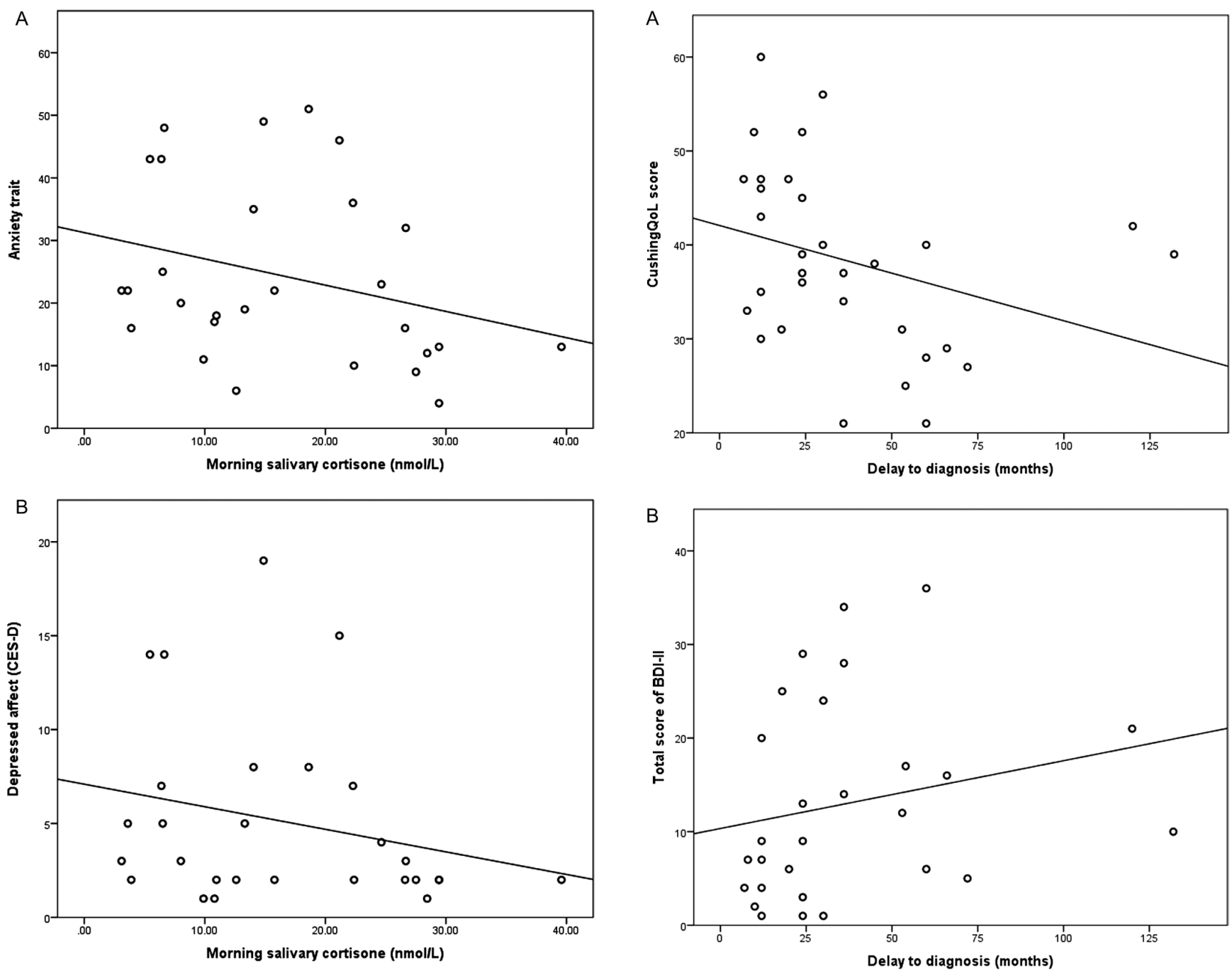

Figure 2

Morning salivary cortisone was inversely associated with (A) anxiety trait of State-Trait Anxiety Inventory (STAI) $(r=-0.377, P=0.040)$ and $(B)$ depressed affect of Center for Epidemiological Studies Depression Scale (CES-D) $(r=-0.392, P=0.032)$ in CS patients in remission.

\section{Discussion}

We have shown that CS patients in long-term remission have low levels of circulating BDNF, which are associated with more anxiety trait, depression and perceived stress, and less affective balance and positive affect, regardless of age and SalF/SalE concentrations. These findings support the hypothesis that BDNF may be a marker of affective state and stress perception in CS patients, even after longterm correction of hypercortisolism. In addition, we have shown that SalE levels early in the morning are inversely associated with anxiety trait and depressed affect.

\section{Figure 3}

Delay to diagnosis was $(A)$ inversely associated with CushingQoL score $(r=-0.460, P<0.01)$ and $(B)$ positively with the total score of the Beck Depression Inventory-II (BDI-II) $(r=0.398, P=0.036)$.

BDNF is an important regulator of the HPA axis adaptive response to stress (40), and its expression is reduced in animal models of depression at the level of the hippocampus and prefrontal cortex, both being important brain regions involved in stress responsivity and emotional functioning (41). In humans, BDNF is being increasingly considered as a biomarker of depression (22). Its serum concentrations decrease in mood disorders, with a negative association with the severity of depression and normalize after successful treatment; this finding being validated after meta-analyses of multiple studies $(22,42,43,44)$. Consistently, we have shown an association between low BDNF and impaired mood 
and stress perception in remitted CS patients but not in matched controls.

BDNF levels have not been studied in patients with active CS thus far but in vivo experiments have demonstrated a negative association between chronic exposure to corticosterone and BDNF expression in the frontal cortex of rats, which is associated with atrophy of the limbic structures regulating the response to stress $(40,45)$. Of note, frontal cortical thining has been previously described in CS patients after longterm remission (19). Interestingly, we have shown a negative association between BDNF and midnight SalF/SalE ratio in our CS patients only. Thus, it may be intriguing to speculate that the observed decrease in BDNF may be one of the persisting abnormalities in 'cured' CS patients after the achievement of eucortisolism and may reflect irreversible structural and/or functional changes in neural circuitries as a consequence of previous exposure to cortisol excess. Of note, serum BDNF has been found to be low in patients who suffered a traumatic brain injury and positively related to cognitive functioning in these subjects, implying that this neurotrophin may be a biomarker of neuronal damage (46).

It is important to highlight that whether serum BDNF entirely reflects BDNF levels in the human brain is still a matter of debate. Although BDNF protein passes the blood-brain barrier (47), and a positive correlation between circulating BDNF concentrations in blood and brain-tissue BDNF levels has been described across species (48), this neurotrophin is also secreted by several peripheral cells, including platelets, leukocytes and endothelial cells (47). Thus, the impact of either central or peripheral BDNF source on our results cannot be determined with certainty. However, some authors have documented a significant relationship between circulating BDNF and some structural/functional brain characteristics in humans $(49,50,51)$. Erickson et al. found that low BDNF levels in serum were associated with age-related decline in hippocampal volume and memory performance (49), whereas Lang et al. demonstrated that serum BDNF was related to intracerebral concentrations of $\mathrm{N}$-acetylaspartate, a marker of neuronal integrity, which they measured in healthy subjects using proton magnetic resonance spectroscopy (50). Moreover, Dalby et al. described a negative association between circulating BDNF concentrations in the blood and white matter integrity, as assessed using diffusion tensor imaging, in the prefrontal cortex of both depressed and healthy subjects (51). Further evidence is needed to confirm our correlative data, and conclusively assess to which degree serum BDNF reflects BDNF levels in the brain.

Another important finding of our study is that morning SalE is inversely related to depressed affect and anxiety trait in 'cured' Cushing's syndrome only, in contrast with SalF, which was not associated with any psychological dimensions in the groups analyzed. Recent evidence suggests that SalE, the predominate glucocorticoid in saliva, may reflect more accurately fluctuations in serum free cortisol (SeF) than SalF (30) and, therefore, may be useful to measure the biological activity of cortisol in several conditions associated with HPA axis dysregulation, including CS and mood disorders (28). Although SalF assessment is clinically used in both endocrine and psychiatric conditions as a diagnostic marker of hypercortisolism (26) and psychological stress (25) respectively, data on SalE in these contexts are scanty. To the best of our knowledge, this is the first time that SalE has been measured in patients who suffered CS and is related to residual morbidity. Moreover, use of LC/TMS to simultaneously assess both SalF and SalE in saliva is a strength of our study, in that this technique allows to overcome the cross-reactivity of cortisone, which has been described to interfere with the accurate measurement of SalF in the most frequently used immunoassays (28).

Although levels of SalE were similar between CS patients in remission and controls, we documented an inverse relationship between morning SalE and measures of mood dysfunction. HPA hypoactivity has been described in patients with atypical depression as well as several stress-related states showing an heterogenous spectrum of depressive symptoms, such as chronic fatigue syndrome and fibromyalgia (52). Dorn et al. found that atypical depression was the most prevalent psychopathology in CS patients one year after remission, and lower morning baseline concentrations of cortisol were related to higher numbers of psychological symptoms, including anxiety, depression and psychoticism (3). This finding led the authors to speculate that derangement of the HPA axis, namely low CRH production or relative glucocorticoid deficiency, may persist for a long term despite correction of hypercortisolism and contribute to the maintanence of affective disorders in remitted CS $(3,53)$. We cannot support this hypothesis, because we did not extensively evaluate the HPA axis responsiveness under stimulated conditions. In addition, although we cannot exclude that some of our patients had relative glucocorticoid deficiency at study entry, hydrocortisone replacement was withdrawn in all of them, after recovery of the HPA axis was confirmed by an ACTH stimulation test (31). 
Although our CS patients in remission showed clear depressive symptomatology and scored worse than controls on several scales assessing mood and affect, they did not meet the criteria for clinical depression, in line with the results of prior studies $(11,16,54)$. This indicates that patients previously exposed to cortisol excess maintain an increased vulnerability to stress, leading to a longstanding 'subtle', but nevertheless clinically relevant, psychopathology. The pathogenesis of this is probably multifactorial, not only including dysregulated HPA axis (44) but also coping strategies and personality traits (16), impaired decision making (19), previous stress induced by suffering a chronic disease (5) and structural/functional alterations of brain regions controlling emotional functioning and stress modulation (17).

In our study, delay to diagnosis was related with depressive symptoms and QoL. Recent evidence suggests that early diagnosis and treatment are clinical predictors of QoL after achieving remission of CD (55). However, we have found that depressive symptomatology is the main negative predictor of QoL rather than delay to diagnosis. Thus, our data suggest that affective alterations, mainly depressive symptoms, might play a pivotal role in affecting patients' wellbeing and daily living after longterm remission, in line with findings observed in active patients (56). Therefore, screening for subtle affective alterations should be included in the regular follow-up of CS patients.

This study has several limitations. The small sample size, an unavoidable drawback of the studies on rare diseases, may also account for the lack of significance in some of the analyses performed. However, these are important preliminary data suggesting that serum BDNF and salivary cortisone might be helpful markers of affective alterations in 'cured' CS patients. Another limitation is its crosssectional design, which prevented us from inferring causalty from these data. In addition, because BDNF plays a role in the regulation of energy homeostasis and food intake, circulating BDNF levels in serum could be influenced by other factors, including body weight and nutritional habits (57).

In conclusion, altered affectivity, mainly anxiety, depressive symptoms, negative affect and stress, persists for a long-term in patients previously treated for CS, and SalE concentrations might be a potential marker of the affective status in these patients. Low levels of BDNF could be involved in the pathophysiology of the affective alterations observed in patients with CS in remission.
Declaration of interest

The authors declare that there is no conflict of interest that could be perceived as prejudicing the impartiality of the research reported.

\section{Funding}

This work was supported in part by Novartis through an Investigator Initiated Trial. E V is recipient of a 'Juan de la Cierva' postdoctoral grant from the Spanish Ministry of Economy and Competitiveness (MINECO).

\section{Acknowledgments}

The authors are indebted to all the subjects participating in this study.

\section{References}

1 Newell-Price J, Bertagna X, Grossman AB \& Nieman LK. Cushing's syndrome. Lancet 2006367 1605-1617. (doi:10.1016/s01406736(06)68699-6)

2 Arnaldi G, Angeli A, Atkinson AB, Bertagna X, Cavagnini F, Chrousos GP, Fava GA, Findling JW, Gaillard RC, Grossman AB et al. Diagnosis and complications of Cushing's syndrome: a consensus statement. Journal of Clinical Endocrinology and Metabolism $2003 \mathbf{8 8}$ 5593-5602. (doi:10.1210/jc.2003-030871)

3 Dorn LD, Burgess ES, Dubbert B, Simpson SE, Friedman T, Kling M, Gold PW \& Chrousos GP. Psychopathology in patients with endogenous Cushing's syndrome: 'atypical' or melancholic features. Clinical Endocrinology 199543 433-442. (doi:10.1111/j.1365-2265.1995.tb02614.x)

4 Kelly WF, Kelly MJ \& Faragher B. A prospective study of psychiatric and psychological aspects of Cushing's syndrome. Clinical Endocrinology 199645 715-720. (doi:10.1046/j.13652265.1996.8690878.x)

5 Sonino N, Fava GA, Raffi AR, Boscaro M \& Fallo F. Clinical correlates of major depression in Cushing's disease. Pshycopathology 199831 302-306. (doi:10.1159/000029054)

6 Webb SM, Badia X, Barahoma MJ, Colao A, Strasburger CJ, Tabarin A, van Aken MO, Pivonello R, Stalla G, Lamberts SW et al. Evaluation of health-related quality of life in patients with Cushing's syndrome with anew questionnaire. European Journal of Endocrinology $2008 \mathbf{1 5 8}$ 623-630. (doi:10.1530/EJE-07-0762)

7 Valassi E, Crespo I, Santos A \& Webb SM. Clinical consequences of Cushing's syndrome. Pituitary 201215 319-329. (doi:10.1007/s11102012-0394-8)

8 Dorn LD, Burgess ES, Friedman TC, Dubbert B, Gold PW \& Chrousos GP. The longitudinal course of psychopathology in Cushing's syndrome after correction of hypercortisolism. Journal of Clinical Endocrinology and Metabolism 199782 912-919. (doi:10.1210/ jc.82.3.912)

9 Heald AH, Ghosh S, Bray S, Gibson C, Anderson SG, Buckler H \& Fowler HL. Long-term negative impact on quality of life in patients with successfully treated Cushing's disease. Clinical Endocrinology 2004 61 458-465. (doi:10.1111/j.1365-2265.2004.02118.x)

10 Van Aken MO, Pereira AM, Biermasz NR, van Thiel SW, Hoftijzer HC, Smit JWA, Roelfsema F, Lamberts SWJ \& Romijm JA. Quality of life in patients after long-term biochemical control of Cushing's disease. Journal of Clinical Endocrinology and Metabolism 200590 3279-3286. (doi:10.1210/jc.2004-1375)

11 Sonino N, Bonnini S, Fallo F, Boscaro M \& Fava GA. Personality characteristics and quality of life in patients treated for Cushing's syndrome. Clinical Endocrinology 200664 314-318. (doi:10.1111/ j.1365-2265.2006.02462.x 
12 Lindsay JR, Nansel T, Baid S, Gumowski J \& Nieman LK. Longterm impaired quality of life in Cushing's syndrome despite initial improvement after surgical remission. Journal of Clinical Endocrinology and Metabolism 200691 447-453. (doi:10.1210/jc.2005-1058)

13 Tiemensma J, Kokshoorn NE, Biermasz NR, Keijser BJ, Wassenaar MJ, Middelkoop HA \& Romijn JA. Subtle cognitive impairments in patients with long-term cure of Cushing's syndrome. Journal of Clinical Endocrinology and Metabolism 201095 2699-2714. (doi:10.1210/jc.2009-2032)

14 Santos A, Resmini E, Martínez-Momblán MA, Crespo I, Valassi E, Roset M, Badia X \& Webb SM. Psychometric paerformance of the Cushing QoL questionnaire in conditions of real clinical practice. European Journal of Endocrinology 2012167 337-342. (doi:10.1530/EJE12-0325)

15 Wagenmakers MAEM, Netea-Maier RT, Prins JB, Dekkers T, den Heijer M \& Hermus ARMM. Impaired quality of life in patients in long-term remission of Cushing's syndrome of both adrenal and pituitary origin: a remaining effect of long-standing hypercortisolism? European Journal of Endocrinology 2012167 687-695. (doi:10.1530/EJE12-0308)

16 Tiemensma J, Biermasz NR, Middlekoop HAM, van der Mast RC, Romijn JA \& Pereira AM. Increased prevalence of psychopathology and maladaptative personality traits after long term cure of Cushing's syndrome. Journal of Clinical Endocrinology and Metabolism 201095 W129-E141. (doi:10.1210/jc.2010-0512)

17 Andela CD, van Haalen FM, Ragnarsson O, Papakokkinou E, Johannsson G, Santos A, Webb SM, Biermasz NR, van der Wee NJA $\&$ Pereira AM. Cushing's syndrome causes irreversible effects on the human brain: a systematic review of structural and functional magnetic resonance imaging studies. European Journal of Endocrinology 2015173 R1-R14. (doi:10.1530/EJE-14-1101)

18 Resmini E, Santos A, Gomez-Anson B, Lopez-Mourelo O, Pires P, Vives-Gilabert Y, Crespo I, Portella MJ, de Juan-Delago M \& Webb SM. Hyppocampal dysfunction in cured Cushing's syndrome patients, detected by 1H-MR spectroscopy. Clinical Endocrinology 201379 700-707. (doi:10.1111/cen.12224)

19 Crespo I, Granell-Moreno E, Santos A, Valassi E, Vives-Gilabert Y, De Juan-Delago M, Webb SM, Gómez-Ansón B \& Resmini E. Impaired decision-making and selective cortical frontal thinning in Cushing's syndrome. Clinical Endocrinology 201481 826-833. (doi:10.1111/ cen.12564)

20 van der Werff SJA, Andela CD, Pannekoek JN, Meijer OC, van Buchem MA, Rombouts SRB, van der Mast RC, Biermasz NR, Pereira AM \& van der Wee NJA. Widespread reductions of white matter integrity in patients with long-term remission. Neuroimage: Clinical 20144 659-667. (doi:10.1016/j.nicl.2014.01.017)

21 Andela CD, van der Werff SJA, Pannekoek JN, van den Berg SM, Mejier OC, van Buchem MA, Rombouts SARB, van der Mast RC, Romijn JA, Tiemensma J et al. Smaller grey matter volumes in the anterior cingulate cortex and greater cerebellar volumes in patients with long-term remission of Cushing's disease: a case-control study. European Journal of Endocrinology 2013169 811-819. (doi:10.1530/EJE13-0471)

22 Autry AE \& Monteggia LM. Brain-derived neurotrophic factor and neuropsychiatric disorders. Pharmacological Reviews 201264 238-258. (doi:10.1124/pr.111.005108)

23 Martinowich K, Manji H \& Lu B. New insights into BDNF function in depression and anxiety. Nature Neuroscience 200710 1089-1093. (doi:10.1038/nn1971)

24 Givalois L, Naert G, Rage F, Ixart G, Arancibia S \& Tapia-Arancibia L. A single brain-derived neurotrophic factor injection modifies hypothalamo-pituitary-adrenocortical axis activity in adult male rats. Molecular and Cellular Neuroscience 200427 280-295. (doi:10.1016/j. mcn.2004.07.002)
25 Hellhammer DH, Wüst S \& Kudielka BM. Salivary cortisol as a biomarker in stress research. Psychoneuroendocrinology 200934 163-171. (doi:10.1016/j.psyneuen.2008.10.026)

26 Nieman LK, Biller BMK, Findling JW, Newell-Price J, Savage MO, Stewart PM \& Montori VM. The diagnosis of Cushing's syndrome: an Endocrine Society Clinical Practice Guideline. Journal of Clinical Endocrinology and Metabolism 200893 1526-1540. (doi:10.1210/ jc.2008-0125)

27 Amlashi FG, Swearingen B, Faje AT, Nachtigall LB, Miller KK, Klibanski A, Biller BM \& Tritos NA. Accuracy of late-night salivary cortisol in evaluating postoperative remission and recurrence in Cushing's disease. Journal of Clinical Endocrinology and Metabolism 2015100 3770-3777. (doi:10.1210/jc.2015-2107)

28 Perogamvros I, Keevil BG, Ray DW \& Trainer PJ. Salivary cortisone is a potential biomarker for serum free cortisol. Journal of Clinical Endocrinology and Metabolism 201095 4951-4958. (doi:10.1210/ jc.2010-1215)

29 Perogamvros I, Owen LJ, Newell-Price J, Ray DW, Trainer PJ \& Keevil BG. Simultaneous measurement of cortisol and cortisone in human saliva using liquid chromatography-tandem mass spectrometry: application in basal and stimulated conditions. Journal of Chromatography B: Analytical Technologies in the Biomedical and Life Sciences 2009877 3771-3775. (doi:10.1016/j.jchromb.2009.09.014)

30 De Bono M, Harrison RF, Whitaker MJ, Eckland D, Artl W, Keevil BG \& Ross RJ. Salivary cortisone reflects cortisol exposure under physiological conditions and after hydrocortisone. Journal of Clinical Endocrinology and Metabolism 2016101 1469-1477. (doi:10.1210/jc.2015-3694)

31 Nieman LK, Biller BM, Findling JW, Murad MH, Newell-Price J, Savage MO \& Tabarin A. Treatment of Cushing's syndrome: an Endocrine Society Clinical Practice Guideline. Journal of Clinical Endocrinology and Metabolism 2015100 2807-2831. (doi:10.1210/ jc.2015-1818)

32 Raff H, Raff JL \& Findling JW. Late-night salivary cortisol as a screening test for Cushing's syndrome. Journal of Clinical Endocrinology and Metabolism 199883 2681-2686. (doi:10.1210/jcem.83.8.4936)

33 Spielberger CD, Gorsuch RL \& Lushene RE. Manual for the State-Trait Anxiety Inventory (Self-Evaluation Questionnaire). Palo Alto, CA, USA: 7 Consultant Psychologists Press, 1970.

34 Beck AT, Steer RA \& Brown GK. Beck Depression Inventory 2. San Antonio, Texas, USA: The Psychological Corporation, 1996.

35 Sanz J, Perdigón A \& Vázquez C. The Spanish adaptation of Beck depression inventory II (BDI-II): psychometric properties in the general population. Clínica Salud 200314 249-280.

36 Radloff LS. The CES-D scale, a self-report depression scale for research in the general population. Applied Psychological Measurement $1977 \mathbf{1}$ 385-401. (doi:10.1177/014662167700100306)

37 Watson D \& Clark LA. Development and validation of brief measures of positive and negative affect: the PANAS scale. Journal of Personality and Social Psychology 198854 1063-1070. (doi:10.1037/00223514.54.6.1063)

38 Cohen S, Kamarck T \& Mermelstein R. A global measure of perceived stress. Journal of Health and Social Behavior 198324 385-396. (doi:10.2307/2136404)

39 Badia X, Herdman M \& Schiaffino A. A determining correspondence between scores on the EQ-5D 'thermometer' and a 5-point categorical rating scale. Medical Care 199937 671-677. (doi:10.1097/00005650199907000-00007)

40 Numakawa T, Adachi N, Richards M, Chiba S \& Kunugi H. Brainderived neurotrophic factor and glucocorticoids: reciprocal influence on the central nervous system. Neuroscience 2013239 157-172. (doi:10.1016/j.neuroscience.2012.09.073)

41 Calabrese F, Molteni R, Cattaneo A, Macchi F, Racagni G, Gennarelli M, Ellenbroek BA \& Riva MA. Long-Term duloxetine treatment normalizes altered brain-derived neurotrophic factor 
expression in serotonin transporter knockout rats through the modulation of specific neurotrophin isoforms. Molecular Pharmacology 201077 846-853. (doi:10.1124/mol.109.063081)

42 Sen S, Duman R \& Sanacora G. Serum brain-derived neurotrophiv factor, depression, and antidepressant medications: meta analyses and implications. Biological Psychiatry 200864 527-532. (doi:10.1016/j. biopsych.2008.05.005)

43 Brunoni AR, Lopes M \& Fregni F. A systematic review and metaanalysis of clinical studies on major depression and BDNF levels: implications for the role of neuroplasticity in depression. International Journal of Neuropsychopharmacology 200811 1169-1180. (doi:10.1017/ S1461145708009309)

44 Polyakova M, Stuke K, Schuemberg K, Mueller K, Schoenknecht P $\&$ Schroeter ML. BDNF as a biomarker for successful treatment of mood disorders: a systematic and quantitative meta-analysis. Journal of Affective Disorders 201574 432-440. (doi:10.1016/j. jad.2014.11.044)

45 Chiba S, Numakawa T, Ninomiya M, Richards MC, Wakabayashi C \& Kunugi H. Chronic restraint stress causes anxiety- and depression-like behaviors, downregulates glucocorticoid receptor expression, and attenuates glutamate release induced by brain-derived neurotrophic factor in the prefrontal cortex. Progress in Neuro-Psychopharmacology and Biological Psychiatry 201239 112-119. (doi:10.1016/j. pnpbp.2012.05.018)

46 Failla MD, Juengst SB, Arenth PM \& Wagner AK. Preliminary associations between brain-derived neurotrophic factor, memory impairment, functional cognition, and depressive symtoms following severe TBI. Neurorehabilitation and Neural Repair 201630 419-430. (doi:10.1177/1545968315600525)

47 Pan W, Banks WA, Fasold MB, Bluth J \& Kastin AJ. Transport of brain-derived neurotrophic factor across the blood-brain barrier. Neuropharmacology 199837 1553-1561. (doi:10.1016/S00283908(98)00141-5)

48 Klein AB, Williamson R, Santini MA, Clemmensen C, Ettrup A, Rios M, Knudsen GM \& Aznar S. Blood BDNF concentrations reflect brian.tissue BDNF levels across species. International Journal of Neuropsychopharmacology 201114 347-353. (doi:10.1017/ S1461145710000738)
49 Erickson KI, Prakash RS, Voss MW, Chaddock L, Heo S, McLaren M, Pence BD, Martin SA, Vieira VJ, Woods JA et al. BDNF is associated with age-related decline in hippocampal volume. Journal of Neuroscience 201030 5368-5375. (doi:10.1523/ JNEUROSCI.6251-09.2010)

50 Lang UE, Hellweg R, Seifert F, Schubert F \& Gallinat J. Correlation between serum brain-derived neurotrophic factor level and an in vivo marker of cortical integrity. Biological Psychiatry 200762 530-535. (doi:10.1016/j.biopsych.2007.01.002)

51 Dalby RB, Elfving B, Poulsen PH, Foldager L, Frandsen J, Videbech P \& Rosenberg R. Plasma brain-derived neurotrophic factor and prefrontal white matter integrity in late-onset depression and normal aging. Acta Psychiatrica Scandinavica 2013128 387-396. (doi:10.1111/acps.12085)

52 Heim C, Ehlert U \& Hellhammer DH. The potential role of hypocortisolism in the pathophysiology of stress-related bodily disorders. Psychoneuroendocrinology 200025 1-35. (doi:10.1016/S03064530(99)00035-9)

53 Chrousos GP \& Gold PW. The concepts of stress and stress system disorders. JAMA 1995267 1244-1252. (doi:10.1001/ jama.1992.03480090092034)

54 Bas-Hoogendam JM, Andela CD, van der Werff JA, Pannekoek JN, van Steenbergen H, Meijer OC, van Buchem MA, Rombouts SARB, van der Mast RC, Biermasz NR et al. Altered neural processing of emotional faces in remitted Cushing's disease. Psychoneuroendocrinology 201559 134-146. (doi:10.1016/j.psyneuen.2015.05.001)

55 Papoian V, Biller BMK, Webb SM, Campbell KK, Hodin RA \& Phitayakorn R. Patients' perception on clinical outcome and quality of life after a diagnosis of Cushing's syndrome. Endocrine Practice 2015 22 51-67. (doi:10.4158/EP15855.OR)

56 Valassi E, Santos A, Yaneva M, Tóth M, Strasburger CJ, Chanson P, Wass JA, Chabre O, Pfeifer M, Feelders RA et al. The European Registry on Cushing's syndrome: 2-year experience. Baseline demographic and clinical characteristics. European Journal of Endocrinology 2011165 383-392. (doi:10.1530/EJE-11-0272)

57 Pillai A, Bruno D, Sarreal AS, Hernando RT, Saint-Louis LA, Nierenberg J, Ginsberg SD, Pomara N, Mehta PD, Zetterberg H et al. Plasma BDNF levels vary in relation to body weight in females. PLoS ONE 20117 e39358. (doi:10.1371/journal.pone.0039358)

Received 13 September 2016

Revised version received 11 November 2016

Accepted 22 November 2016 